\title{
Heat transfer model for PV module with cooling channel
}

\author{
Anna Opiela, and Zbigniew Zapałowicz ${ }^{*}$
}

Department of Heat Engineering, Faculty of Mechanical Engineering and Mechatronics, West Pomeranian University of Technology, Szczecin, al. Piastów 17, 70-310 Szczecin, Poland

\begin{abstract}
The paper presents heat transfer model for a PV module with the cooling channel. The model has been applied to elaborate a calculation algorithm in order to estimate the power of PV module in relation to its temperature. The proposed calculation methodology allows to evaluate the amount of energy produced by PV installation in the fixed time scale.
\end{abstract}

\section{Nomenclature}

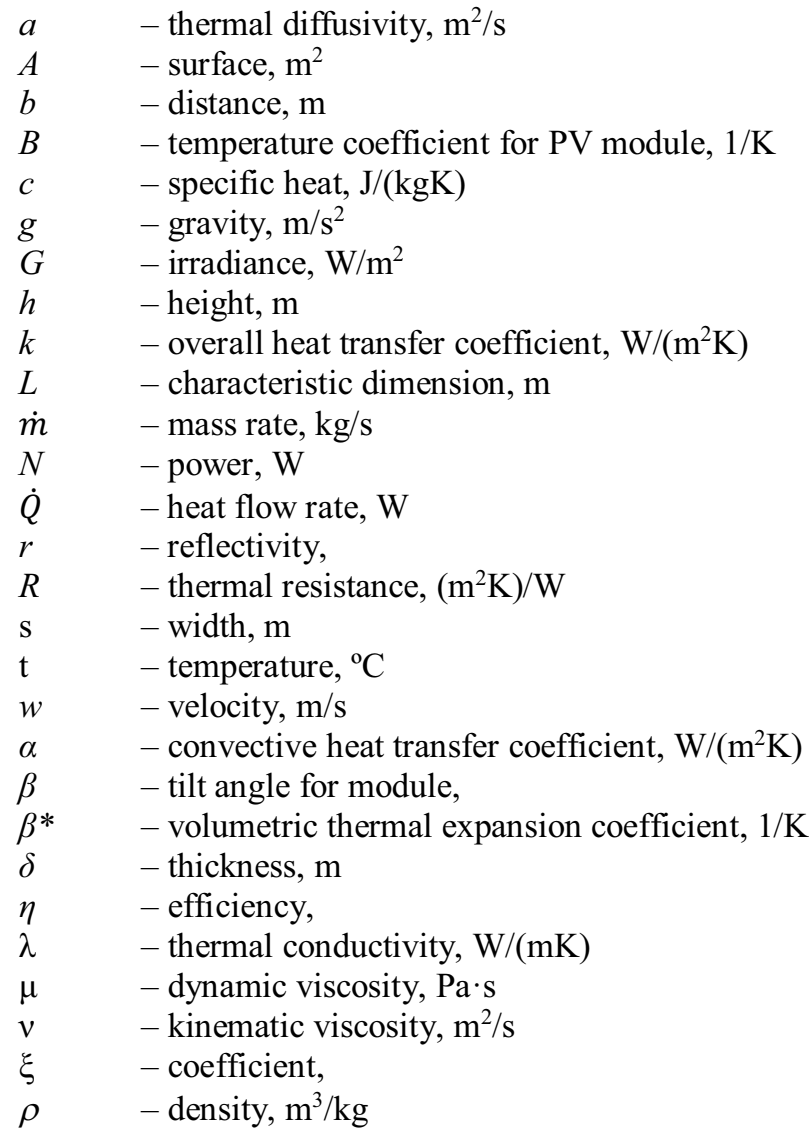

\section{Subscripts}

$$
\begin{array}{ll}
A & - \text { ambient } \\
B & - \text { lateral wall } \\
c & - \text { contact (p-n junction) } \\
\text { el } & \text { - electrical }
\end{array}
$$

\footnotetext{
*Corresponding author: zbigniew.zapalowicz@zut.edu.pl
}

$$
\begin{array}{ll}
f & \text { - fluid } \\
F & \text { - front } \\
K & \text { - channel } \\
M & \text { - module } \\
N & \text { - horizon } \\
R & \text { - room } \\
S & \text { - sun } \\
S T C & \text { - Standard Test Condition } \\
T & \text { - rear } \\
w & \text { - wind } \\
W & \text { - wall }
\end{array}
$$

Indices

$$
\begin{array}{ll}
k & - \text { convection } \\
\mathrm{p} & - \text { conduction } \\
r & - \text { radiation }
\end{array}
$$

Criterial number

$$
\begin{array}{ll}
G r & - \text { Grashof number, } G r=\left(\beta^{*} g L^{3} \Delta T\right) / v^{2} \\
N u & \text { - Nusselt number, } N u=\alpha L / \lambda \\
\mathrm{Pr} & \text { - Prandtl number, } \operatorname{Pr}=v / a \\
\mathrm{Re} & \text { - Reynolds number, } \operatorname{Re}=w L / v
\end{array}
$$

\section{Introduction}

One of development tendency in modern solar power engineering is increase of efficiency of PV modules. Technical data of PV modules given by manufacturers in their catalogues are defined in STC conditions (Standard Test Conditions), and they can only by chance correspond with real conditions. Therefore, nominal power parameters of PV modules assumed by the choice of elements for the installation differ from power values obtained in practical applications. Temperature of 
$\mathrm{p}-\mathrm{n}$ junction is one of relevant factors that decide about the instantaneous power of PV module. The higher the value of this temperature, the lower the power of PV module, and so the lower the energy production in the PV installation [1]. That is the reason, why it is aimed at lowering the temperature of $\mathrm{p}-\mathrm{n}$ junction by cooling the rear wall of PV module. There are a few ways to obtain the aim: convection cooling by a fluid stream (air, water, low-boiling fluids), cooling with application of PCM materials, thermoelectric cooling, or spraying the surface with a droplets stream [2-4]. Authors of the present paper propose the heat transfer model with cooling channel, which allows to determine in an iterative way the approximate temperature of the p-n junction for the fixed time scale. Which, in turn, enables to determine the instantaneous electric power of PV module. Further, if time discretization is made, determination of approximate energy production in fixed time scales is possible. Of course, amount of produced energy depends on the local value of irradiance. The proposed model is a modified version of the model discussed in paper [2].

\section{Model}

In order to estimate the instantaneous electric power of PV module with cooling channel, energy balance was made for PV module and for the fluid in cooling channel, separately.

In case of PV module, it is assumed that, as a result of instantaneous balance of fluxes of input and output energies, module's temperature is the same in all its volume, with exception for the p-n junction only. Energy balance equation for PV module treated as one body has the form (Fig.1):

$$
\begin{aligned}
\dot{Q}_{M F}^{r}= & \dot{Q}_{M F-N}^{r}+\dot{Q}_{M F-A}^{k}+\dot{Q}_{M B-A}^{k}+\dot{Q}_{M T-f}^{k}+ \\
& +\dot{Q}_{M T-f}^{r}+N_{e l}+\dot{Q}_{e l}^{p}+\Delta \dot{Q}_{M}
\end{aligned}
$$

The following simplifying assumptions were applied in further analysis:

- steady state of PV module; the state occurs when $\Delta \dot{Q}_{M}=0$ in PV module, if the heat capacities of PV layers are neglected,

- heat flow rates: carried away by conductors $-\dot{Q}_{e l}^{p}$, transferred by radiation between the rear wall of PV module and the air in the channel $-\dot{Q}_{M T-f}^{r}$, transferred by radiation between the front wall of PV module and horizon $-\dot{Q}_{M F-N}^{r}$, transferred through the lateral walls of the module $-\dot{Q}_{M B-A}^{k}$, and can be neglected,

- $\quad$ solar radiation - $\dot{Q}_{M F}^{r}$, on the p-n junction.

Then, after considering the above assumptions, energy conservation equation (1) has the form:

$$
\dot{Q}_{M F}^{r}=\dot{Q}_{M F-A}^{k}+\dot{Q}_{M T-f}^{k}+N_{e l}
$$

or

$$
\frac{\dot{Q}_{M F-A}^{k}}{\dot{Q}_{M F}^{r}}+\frac{\dot{Q}_{M T-f}^{k}}{\dot{Q}_{M F}^{r}}+\frac{N_{e l}}{\dot{Q}_{M F}^{r}}=1
$$

If using respective coefficients equation (3) has the form:

$$
\xi_{M F-A}^{k}+\xi_{M T-f}^{k}+\xi_{e l}=1
$$

Solar radiation reaching the front side of PV module is partially reflected from the anti-reflective coating therefore:

$$
\dot{Q}_{M F}^{r}=\left(1-r_{M F}\right) \cdot G_{S-M F}^{r} \cdot A_{M F}
$$

Heat flow rates transferred between PV module, and environment and fluid on the other hand are given by equations:

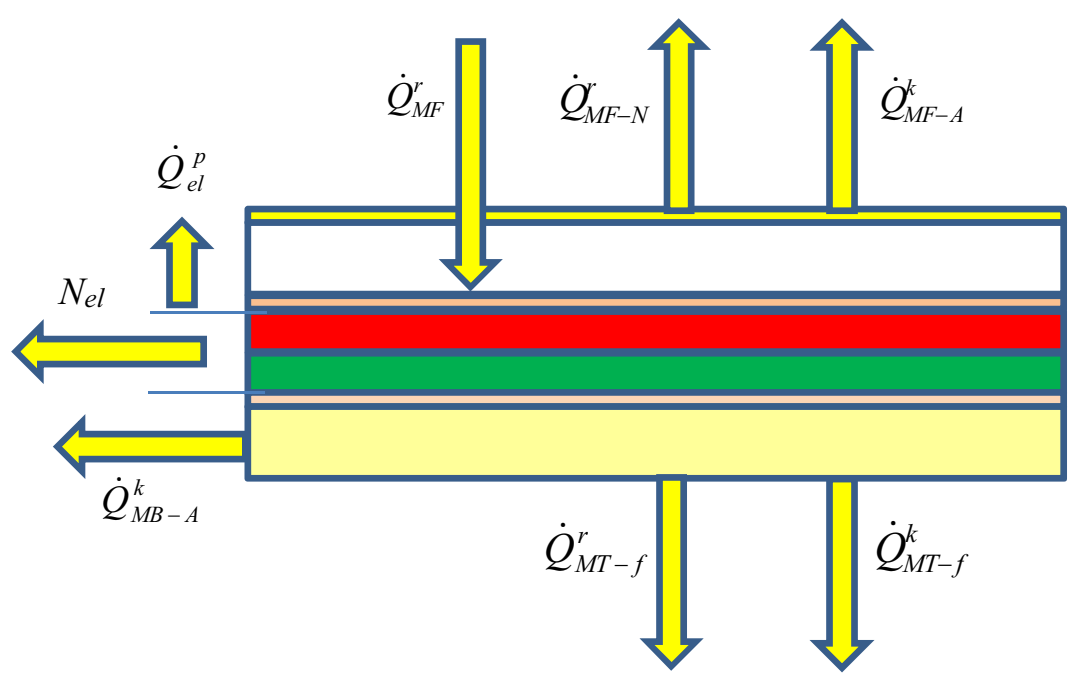

Fig.1. Energy streams in PV module. 


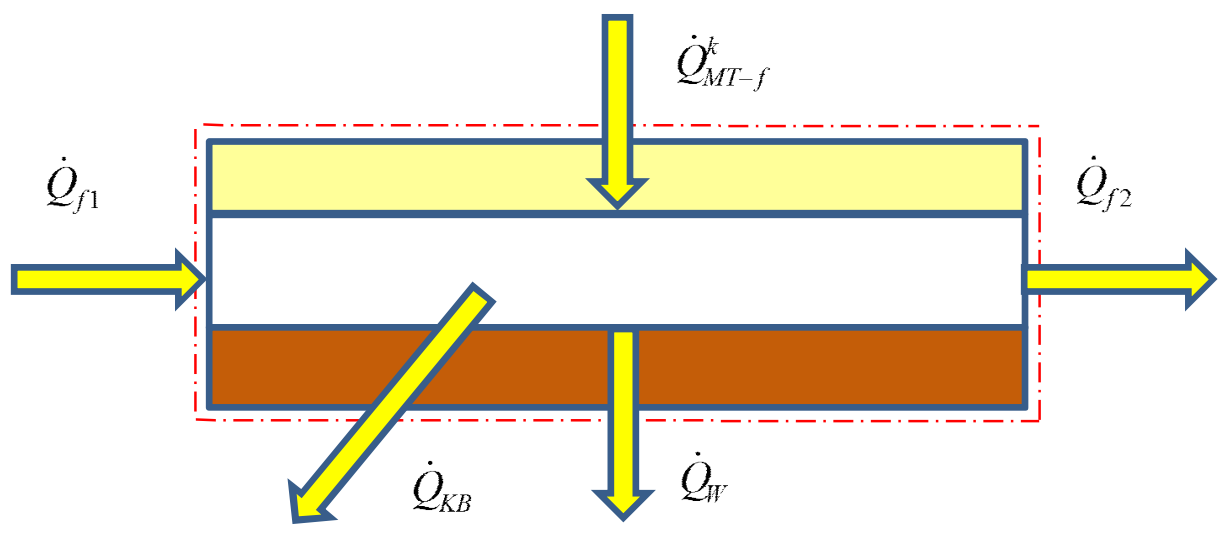

Fig.2. Heat flow rates for cooling fluid flowing in the channel.

$$
\begin{gathered}
\dot{Q}_{M F-A}^{k}=\alpha_{M F-A} \cdot A_{M F-A} \cdot\left(t_{M F}-t_{A}\right) \\
\dot{Q}_{M T-f}^{k}=\alpha_{M T-f} \cdot A_{M T-f} \cdot\left(t_{M T}-t_{f}\right)
\end{gathered}
$$

In turn, energy balance for the cooling fluid flowing in the channel (Fig.2) has the form:

$$
\dot{Q}_{M T-f}^{k}+\dot{Q}_{f 1}=\dot{Q}_{f 2}+\dot{Q}_{K B}+\dot{Q}_{W}
$$

or

$$
\xi_{M T-f}^{k} \cdot \dot{Q}_{M F}^{r}+\dot{Q}_{f 1}=\dot{Q}_{f 2}+\dot{Q}_{K B}+\dot{Q}_{W}
$$

Energy flow rates of the cooling fluid at the inlet and outlet from the channel can be determined from relations:

$$
\begin{aligned}
& \dot{Q}_{f 1}=\dot{m}_{f 1} \cdot c_{f 1} \cdot t_{f 1}=w_{f 1} \cdot A_{f 1} \cdot \rho_{f 1} \cdot c_{f 1} \cdot t_{f 1} \\
& \dot{Q}_{f 2}=\dot{m}_{f 2} \cdot c_{f 2} \cdot t_{f 2}=w_{f 2} \cdot A_{f 2} \cdot \rho_{f 2} \cdot c_{f 2} \cdot t_{f 2}
\end{aligned}
$$

Heat flow rate carried away from the fluid in the channel as a result of heat transfer through the wall is equal to:

$$
\dot{Q}_{W}=k_{f-W} \cdot A_{W} \cdot\left(t_{f}-t_{R}\right)
$$

Heat flow rate conducted through lateral protective walls of the channel can be estimated as:

$$
\dot{Q}_{K B}=2 \cdot k_{f-B} \cdot A_{B} \cdot\left(t_{f}-t_{A}\right)
$$

Besides, it is assumed that temperature of the fluid in the channel is a mean of its temperatures at the inlet and at outlet of the channel:

$$
t_{f}=\frac{t_{f 1}+t_{f 2}}{2}
$$

After substitution of relation (10) - (14) in energy conservation equation for the fluid (9) the following equation is obtained:

$$
\begin{gathered}
\xi_{M T-f}^{k} \cdot \dot{Q}_{M F}^{r}+w_{f 1} \cdot A_{f 1} \cdot \rho_{f 1} \cdot c_{f 1} \cdot t_{f 1}= \\
=w_{f 2} \cdot A_{f 2} \cdot \rho_{f 2} \cdot c_{f 2} \cdot t_{f 2}+ \\
+2 \cdot k_{f-B} \cdot A_{B} \cdot\left(\frac{t_{f 1}+t_{f 2}}{2}-t_{A}\right)+ \\
+k_{f-W} \cdot A_{W} \cdot\left(\frac{t_{f 1}+t_{f 2}}{2}-t_{R}\right)
\end{gathered}
$$

From the above equation, temperature of fluid at the outlet from the channel can be determined as:

$$
\begin{gathered}
t_{f 2}=\frac{\xi_{M T-f}^{k} \cdot \dot{Q}_{M F}^{r}}{w_{f 2} \cdot A_{f 2} \cdot \rho_{f 2} \cdot c_{f 2} \cdot+k_{f-B} \cdot A_{B}+0,5 \cdot k_{f-W} \cdot A_{W}}+ \\
+\frac{\left(w_{f 1} \cdot A_{f 1} \cdot \rho_{f 1} \cdot c_{f 1}-k_{f-B} \cdot A_{B}-0,5 \cdot k_{f-W} \cdot A_{W}\right) \cdot t_{f 1}}{w_{f 2} \cdot A_{f 2} \cdot \rho_{f 2} \cdot c_{f 2}+k_{f-B} \cdot A_{B}+0,5 \cdot k_{f-W} \cdot A_{W}}+ \\
+\frac{2 \cdot k_{f-B} \cdot A_{B} \cdot t_{A}-k_{f-W} \cdot A_{W} \cdot t_{R}}{w_{f 2} \cdot A_{f 2} \cdot \rho_{f 2} \cdot c_{f 2} \cdot+k_{f-B} \cdot A_{B}+0,5 \cdot k_{f-W} \cdot A_{W}}
\end{gathered}
$$

Then, temperature $t_{f}$ can be determined from equation (14), and next, temperature of rear wall of PV module can be determined from equation (7):

$$
t_{M T}=t_{f}+\frac{\xi_{M T-f}^{k} \cdot \dot{Q}_{M F}^{r}}{\alpha_{M T-f} \cdot A_{M T-f}}
$$

Temperature of $\mathrm{p}-\mathrm{n}$ junction can be calculated from equation [5]:

$$
t_{c}=t_{M T}+\frac{G_{S-M F}^{r}}{G_{0}} \cdot \Delta t
$$

where: $G_{0}-$ referential irradiance $\left(G_{0}=1000 \mathrm{~W} / \mathrm{m}^{2}\right)$, $\Delta t$ - temperature difference of PV module n-p junction and of its rear wall at referential irradiance. 
Thus, electrical efficiency of PV module resulting from current temperature of the $p$-n junction is described by equation:

$$
\begin{aligned}
\eta_{e l} & =\eta_{e l_{-} S T C} \cdot\left[1-\frac{B_{N}}{100}\left(t_{c}-t_{S T C}\right)\right]= \\
& =\eta_{e l_{-} S T C} \cdot\left[1-\frac{B_{N}}{100}\left(t_{c}-25\right)\right]
\end{aligned}
$$

where $B_{N}$ is coefficient of power change with temperature (given by the producer).

Power of PV module can be calculated from equation:

$$
N_{e l}=N_{e l_{-} S T C} B_{P V}\left(\frac{G_{S-M F}^{r}}{G_{S T C}}\right) \cdot\left(\frac{\eta_{e l}}{\eta_{e l_{-} S T C}}\right)
$$

Coefficient $B_{P V}$ in equation (20) describes the degree of drop of nominal parameters of the module depending on operation conditions. The coefficient relates to such factors like smudges on the module, losses on conductors, shading, snow covering, ageing etc. $B_{P V}=1$ is assumed in the paper.

It is also necessary for calculations to determine convective heat transfer coefficients, overall heattransfer coefficients among particular media, or respective thermal resistance values.

Overall heat-transfer coefficient through the lateral wall of the channel depends on its thermal resistance and can be calculated from equation:

$$
k_{f-B}=\frac{1}{R_{f-B}}=\frac{1}{\frac{1}{\alpha_{f-B}}+\frac{\delta_{B}}{\lambda_{B}}+\frac{1}{\alpha_{B-A}}}
$$

In turn, heat transfer coefficient through the building wall can be determined from the relation:

$$
k_{f-W}=\frac{1}{R_{f-W}}=\frac{1}{\frac{1}{\alpha_{f-W}}+\frac{\delta_{W}}{\lambda_{W}}+\frac{1}{\alpha_{W-R}}}
$$

Convective heat transfer coefficient from the front wall of PV module to the environment is given by the equation:

$$
\alpha_{M F-A}=\frac{\lambda_{A}}{h_{A}} \cdot N u_{A}
$$

In order to determine this coefficient, knowledge of Nusselt empirical correlations describing overflowing the module's front wall by air is required. The relations are given among other in paper [6] (e.g. relations of Mitchel, Mc Adams, or Shewen). The choice of Nusselt empirical correlation results from site and kind of mounting of the PV module on the wall of the building.
Also, a simplified relation considering additional effect of wind can be applied for calculations, e.g.:

$$
\alpha_{M F-A}=2,8+3,0 \cdot w_{w}
$$

Besides, it has been assumed that the process of overflowing the lateral walls of the channel by air is the same as the process of overflowing the front wall of PV module, hence:

$$
\alpha_{B-A}=\alpha_{M F-A}
$$

Convective heat-transfer coefficient from rear wall of PV module to the fluid in the channel can be determined from relations valid for the flow of the fluid in the narrow channel [7]. Heat transfer in a confined channel by natural convection is treated as heat conduction. The equivalent convective heat-transfer coefficient $\lambda_{f}^{*}$ relates to both: the process of heat conduction and heat convection in the channel.

General empirical correlation describing heat transfer in the narrow channel has the form:

$$
\frac{\lambda_{f}^{*}}{\lambda_{f}}=C \cdot(G r \cdot \operatorname{Pr})^{\mathrm{a}}
$$

The choice of empirical correlation for calculations depends on the width and length of the channel; in case of PV module, it depends on $b / h_{M}$ ratio.

Then, convective heat-transfer coefficient can be determined from the equation:

$$
\alpha_{M T-f}=\frac{\lambda_{f}^{*}}{b}
$$

In case of forced convection in the channel, the choice of empirical relation depends on the kind of flow. Then, general empirical equation has the form:

$$
N u_{f}=C \cdot \operatorname{Re}^{b} \cdot \operatorname{Pr}^{\mathrm{c}}
$$

It is assumed for calculations that values of convective heat-transfer coefficients from the liquid in the channel to the lateral wall of the channel, and from the liquid to the building wall meet the following relation:

$$
\alpha_{M T-f}=\alpha_{f-B}=\alpha_{f-W}
$$

Convective heat transfer coefficient from the building wall to the air indoors can be determined from the equation:

$$
\alpha_{W-R}=\frac{\lambda_{R}}{h_{R}} \cdot N u_{R}
$$


Paper [6] gives empirical correlations describing the heat transfer between environment and indoors, relating to direction of heat flow and inclination of building wall.

\section{CALCULATION METHODOLOGY}

In order to determine the instantaneous working parameters of PV module, data for calculations and initial conditions should be given.

The first group of data requires the technical data of the module (power $N_{e l_{-} S T C}$, efficiency $\eta_{e l_{-} S T C}$, coefficient $B_{N}$, temperature difference $\Delta t$ at referential irradiance, reflexivity coefficient $r_{M F}$ and module's width $s_{M}$ and length $h_{M}$ ). It is easy to determine the gross surface area of PV module on the basis of its geometrical dimensions, from the equation:

$$
A_{M}=s_{M} \cdot h_{M}
$$

It can be assumed for further calculations that:

$$
A_{M}=A_{M F}=A_{M F-A}=A_{M T-f}=A_{W} .
$$

Cooling channel can be an integral part of PV module, but it can also be a separate heat exchanger mounted on its rear wall, as well. It is assumed in the present paper that the channel is created between the rear wall of the module and the building wall. Then, PV module is placed on a frame fastened to the building wall in distance $b$. Lateral walls of the channel are additional constructional elements. Parameters of the lateral walls of the channel are known: $\delta_{B}, \lambda_{B}$. Thus, it is possible to determine cross section areas on inlet and outlet from the channel, as well as surface area of lateral walls of the channel, from the following equations, respectively:

$$
\begin{aligned}
& A_{f 1}=A_{f 2}=b \cdot s_{M} \\
& A_{B}=2 \cdot b \cdot h_{M}
\end{aligned}
$$

The latter data group concerns parameters of solar radiation and parameters of environment. The data depends on the site of PV installation location (latitude and longitude). Database collecting parameters of solar radiation and of environment supplies among other: global irradiance reaching the horizontal or inclined surface directed respectively to the sun, for the fixed day of the year and for the fixed hour. The above data allows to determine the irradiance $G_{S-M F}^{r}$, ambient temperature $t_{A}$, and wind velocity $w_{w}$.

It is also required for calculations to know the kind of fluid and its initial temperature $t_{f 1}$. Then, it is possible to determine physical parameters of the fluid.

Flow of the fluid in the channel can result from natural convection, or it can be the motion constrained by a transporting device (pump, fan). In case of natural convection, mean velocity of transportation of fluid in the channel can be determined from equation [8]:

$$
w_{f}=\frac{b^{2} g \beta^{*} \cdot \sin \beta}{12 \mu_{f}}
$$

As it has been mentioned, the channel is limited by building wall made of materials with known physical parameters, that is, thickness $\delta_{W}$ and thermal conductivity $\lambda_{W}$. It can be assumed in calculations that air temperature indoors is constant and relates to conditions of thermal comfort, that is $t_{R}=20 \div 22{ }^{\circ} \mathrm{C}$.

In the first calculation step, it can be assumed that initial value of $\mathrm{p}$-n junction temperature equals $t_{c}=t_{S T C}=25^{\circ} \mathrm{C}$, then, initial electrical efficiency of PV module calculated from equation (19) is $\eta_{e l_{-} S T C}$. Thus, initial power of PV module $N_{e l}$ depends only on the current value of parameter $G_{S-M F}^{r}$. Next, coefficient $\xi_{e l}$ can be determined from the equation:

$$
\xi_{e l}=\frac{N_{e l}}{\dot{Q}_{M F}^{r}}
$$

Besides, it is initially assumed that heat flow rates transferred from PV module to environment and to the air in the channel have the same values, that is $\dot{Q}_{M F-A}^{k}=\dot{Q}_{M T-f}^{k}$, thus it results from Eq.4 that:

$$
\xi_{M T-f}^{k}=\xi_{M F-A}^{k}=0,5 \cdot\left(1-\xi_{e l}\right)
$$

In the first calculation step, determination of physical properties of fluid on the outlet from the channel is impossible while temperature $t_{f 2}$ is unknown. That is why it can be assumed that physical properties of fluid are equal on inlet and outlet. In further calculations steps, properties of fluid on output are determined for temperature $t_{f 2}$ calculated in the previous calculations step.

Output temperature $t_{f 2}$ is calculated in succeeding iterative steps up to the moment when its value reaches the demanded accuracy. If verifying condition is met, it is due to calculate all parameters relevant for operation of PV installation, and move on to the next cycle of calculations.

\section{SUMMARY}

The paper presents the model and calculations methodology that allow to determine working parameters for PV module with cooling channel. Proposed model has a general character and allows to choose calculations relations depending on required technical situation. The model, as well as given calculations methodology will be verified experimentally. 


\section{REFERENCES}

1. S. Dubey, J.N. Sarvaiya, B. Seshadri, Energy Procedia, 33, 311-322, (2013)

2. A. Opiela, Z. Zapałowicz, Polska Energetyka Słoneczna. No.1-4, 13-17, (2013)

3. J. Park, T. Kim, S-B. Leigh, Solar Energy, 105, 561574, (2014)

4. K.A. Moharram, M.S. Abd-Elhady, H.A. Kandil, H. El-Sherif. Ain Shams Engineering Journal, No.4, 869-877, (2013)
5. https://pvpmc.sandia.gov/modeling-steps/2-dcmodule-iv/module-temperature. (25-02-2016)

6. D. Chwieduk, Energetyka stoneczna budynku (Wyd. Arkady, Warszawa, 2011)

7. B. Staniszewski: Wymiana ciepla. Podstawy teoretyczne (PWN, Warszawa, 1980)

8. E. Klugmann-Radziemska, E. Klugmann, Systemy stonecznego ogrzewania $i$ zasilania elektrycznego budynków (Wyd. Ekonomia i Środowisko. Białystok, 2002) 